\title{
ENTRE DITOS, NÃO DITOS E MALDITOS: O INOMINÁVEL NA POESIA DE HILDA HILST
}

Geruza Zelnys de Almeida*

\begin{abstract}
Resumo: O objetivo deste estudo é analisar a construção na poesia metafísica da escritora brasileira Hilda Hilst, a partir da física ou da materialidade da linguagem poética. Para isso, analisamos os procedimentos poéticos que promovem a indissolubilidade entre forma e idéia nos poemas. Os resultados analisados demonstram que, harmonizando o desejo metafísico com o rigor científico, Hilda torna visível a estrutura diagramática do pensamento, desenhando a metafísica dentro da física poética - primeiro, através de linhas ascendentes em busca do sublime e, segundo, por meio de linhas descendentes rumo ao grotesco.
\end{abstract}

Palavras-Chave: Hilda Hilst, Poesia, Metafísica, Física.

Hilda Hilst (1930-2004) gostava de enfatizar que toda sua obra era uma incansável busca por Deus e, inclusive na literatura dita pornográfica, observamos que é sempre essa perseguição que a move. Diz-se perseguição porque Hilda é uma poeta do excesso, que se estende em palavras, dentro do que Pound (1991) classifica como "bom verbalismo”: atitude que requer o domínio de uma linguagem extremamente culta.

Nos textos hilstianos, essa característica é intrínseca ao fluxo do pensamento, que nunca é estático, mas está sempre em movimento à procura da exatidão e das palavras justas. Mas, a que se deve a exatidão ímpar que acompanha a leitura do invisível-indizível metafísico nesta criação poética?

Primeiramente, a necessidade de colocar a razão em experimentação, até os limites do sensível, toma corpo na poesia hilstiana, caracterizando-a como um verdadeiro exercício de construção do conhecimento. Tão forte é o desejo de dar forma concreta ao pensamento metafísico que Hilda cria “esquemas” rítmicos, sonoros e visuais para construir uma homologia entre o objeto da atenção e sua representação, experimentando e modificando os diagramas mentais a fim de testar hipóteses. É cabível, portanto, dizer que a poeta porta-se como uma cientista à medida que aprimora e avança nos estudos poético-metafísicos.

Mesmo os físicos da modernidade salientam o parentesco entre o pensamento poético e o pensamento matemático. Schenberg, no livro Pensando a Física (2001), em sintonia com os “estados poéticos” valerianos, aponta as quatro fases de uma criação científica: o aparecimento de uma idéia, seu conseqüente abandono, a solução inesperada e, por fim, o trabalho de aperfeiçoamento da fórmula matemática. Daí que “as idéias fundamentais da física e da matemática

\footnotetext{
* Doutoranda no Departamento de Teoria Literária e Literatura Comparada da USP. Professora no curso de especialização em Literatura da PUC-COGEAE-SP. E-mail para contato: zelnys@hotmail.com
} 
não são coisas puramente racionais; muitas vezes têm origem misteriosa” (SCHENBERG, 2001: $31)$.

Entretanto, no espaço informe da poesia, a tentativa de materialização do ser por meio da palavra poética coloca a autora frente a uma impossibilidade nascida no fracasso da língua para dizer e/ou presentificar o todo. Em luta contra a falibilidade sígnica, Hilda se mostra insatisfeita com os nomes, iniciando, assim, um profundo trabalho de re-nomeação do ser no intuito de fundir palavra-coisa. Para isso, chega às últimas conseqüências mergulhando no sensível para encontrar o incognoscível por meio da 'sensualização' da forma (o movimento erotizante do pensamento) e até da pornografia vernacular.

Se, para Chang-Tung-Sun, a função de renomear é "discernir o que fica em cima e o que fica em baixo, determinar o superior e o inferior e distinguir o bem do mal” (ㅁpud CAMPOS, 2000: 194); na poética hilstiana esse procedimento pode ser tomado como a busca humana pelo conhecimento por meio de uma lógica de purificação conceitual. Explica-se: sendo o nome carregado de significação simbólica, via de regra ele aponta para um conceito padronizado. Como a poética hilstiana mira a construção, há a tentativa de purificar os nomes, destituindo-lhes os significados convencionais e buscando, em novos denominadores, significações novas que, possivelmente, construirão novos conceitos.

Octávio Paz, em O arco e a lira, afirma que "a primeira coisa que o homem faz diante de uma realidade desconhecida é nomeá-la, batizá-la [porque] aquilo que ignoramos é o inominado” (PAZ, 1982: 37). Portanto, se nomear é conhecer, o nomeado, quando se mantém desconhecido ou inalcançável, reclama uma re-nomeação, nem que seja, ao menos, para criar uma ilusão de conhecimento que satisfaça o intelecto. Por isso, Hilda tece infinitos nomes à procura da imagem/idéia inaugural, que a aproxime do ser, re-ordenando e re-criando conceitos, numa tentativa de conhecer os símbolos pela forma como se indiciam.

Esse procedimento desemboca numa espécie de ritual de cópula imagética, ou seja, o movimento frenético das imagens funde-as num todo prenhe de significação. Está aí a natureza erótica da poética hilstiana, uma vez que a busca do erotismo é a fusão e, segundo Bataille, eliminação dos limites que viola as identidades e possibilita a total comunhão entre um e outro ser (MORAES, 2002: 50).

Observa-se esse procedimento em Da morte. Odes Mínimas. (2003), tortuoso monólogo poético - composto de quarenta poemas - dirigido à Morte, ou melhor, à sua "consciência” da morte: 
Te batizar de novo.

Te nomear num trançado de teias

E ao invés de Morte

Te chamar Insana

Fulva

Feixe de Flautas

Calha

Candeia

Palma, por que não?

Te recriar nuns arco-íris

Da alma, nuns possíveis

Construir teu nome

E cantar teus nomes perecíveis:

Palha

Corça

Nula

Praia

Por que não? (HILST, 2003: I, 29)

Para chegar até o Deus desejado, a poeta busca a morte, estado limítrofe entre corpo e espírito, abismo entre o ser desejoso e o desejado, procurando conhecê-la em sua singularidade, ou seja, na inscrição do próprio nome. Insatisfeita com a morte (des)conhecida, a poeta recria a mortenome, a partir do material vocabular "perecível” de que dispõe, atribuindo-lhe novas nomenclaturas e tornando-a, assim, mais atraente. Por meio de atributos imagéticos, sonoros, sensíveis e intelectivos, fornecidos pelos substantivos ou adjetivos substantivados, funda-se uma morte poética, na qual as palavras vão se aproximando por suas parecenças e se aglutinando melopaicamente (fulva/feixe/flauta). Nesses versos monossilábicos, a morte adquire um ritmo dançante que a sensualiza e a destitui do significante morte, eliminando, assim, o temor contido na construção anagramática.

Entretanto, o conhecimento integral não cabe ao ser humano e, assim, ao longo da composição, cria-se um movimento erotizante de aproximação e afastamento que leva à inversão de papéis: ao invés de ser tomada pela morte, a poeta toma-a sensorialmente: se pensá-la lhe é possível em vida, senti-la é condição imposta pelo morrer:

Se eu soubesse

Teu nome verdadeiro

Te tomaria

Úmida, tênue (HILST: XIX, 47)

É nesse sentido que o re-conhecimento hipotético se ampara “nuns possíveis” imagéticosonoro-visuais e não, apenas, abstrato-conceituais. Esses possíveis sugerem a presença da probabilidade, pois no embate entre imagens convergentes e divergentes pode haver mais de um ponto de acumulação (SCHENBERG, 2001: 163). 
A pergunta "por que não?” reafirma a postura do cientista - e do princípio da incerteza ${ }^{1}$ disposto a conhecer, materialmente, os domínios da própria metafísica, além de manter acesa a proposta do encontro, ou ainda, da fusão entre o conhecido e o desconhecido: "Que eu te conheça lícita, terrena” (HILST: II, 30); “Há milênios te sei / E nunca te conheço.” (HILST: III, 31).

Trazendo a Morte para perto de si, a poeta desfia infinitas redes de significação que vão se avolumando no poema, desagregando o conceito convencional para a imagem-Morte. Este conceito primeiro desliza por imagens outras, recebendo pinceladas que redimensionam seu traçado:

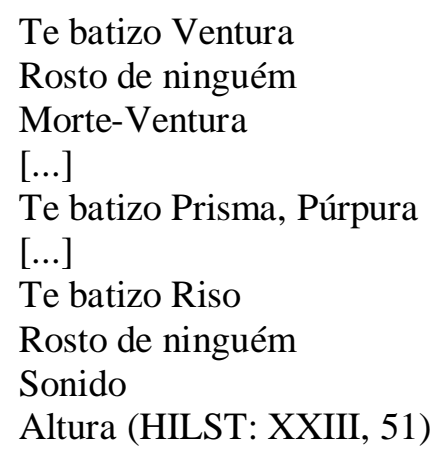

A linha geométrica que se estende infinitamente, em direção ao sublime, encontra-se fadada ao fracasso de "re-nomear" o que não cabe numa palavra. Como a verdade não se força aos olhos, a poesia não revela numa palavra toda sua verdade: a morte se mostra na potência da língua que é impotente para lhe dizer, mas que fixa nesse campo magnético-textual, entre o dito e o não-dito, sua essencialidade (BADIOU, 2002: 39).

Assim, para se aproximar o máximo possível da “verdade” da Morte, desenha-se um corpo físico, por meio de inúmeras imagens, na tentativa de traçar um recorte que separe o ser da morte de seu infinito possível: Cavalinha, Cavalo, Búfalo, e, principalmente, Cobra. A imagem da cobra aparece nos estudos de Valéry, apontados por Augusto de Campos em Valéry: a serpente e o pensar, associada ao "ícone do pensar"²: a serpente pelo aspecto espiralado e pela formação em nós representa o pensamento em movimento. Bem por isso, na plasticidade dos poemas que compõem Da morte... construída por meio da fanopéia, cristaliza-se a serpente valeriana esgueirando-se em contínuos retornos e metamorfoses, provocando na memória as reminiscências de um passado bíblico:

\footnotetext{
${ }^{1}$ Observa-se que a complexidade da imagem, que não permite resolução exata, nos remete ao "princípio de incerteza” da Física. Platão dizia que um elemento podia transformar-se em outro, assim, "um poliedro de faces triangulares podia ter esses triângulos separados e depois juntados novamente numa forma diferente, dando-se então a transmutação dos elementos" (SCHENBERG, 2001: 28).

2 “A Serpente é, pois, acima de tudo, na simbólica valeriana, o ícone do pensar - uma atividade que ele tentou conduzir aos limites extremos: 'Acostumar-se a pensar como a Serpente (penser en Serpent) que se come pela cauda. Pois aí está toda a questão. Eu ‘contenho’ o que me ‘contém’. E eu sou sucessivamente continente e conteúdo”. (VALERY Apud CAMPOS, 1984: 11).
} 
Vinda do fundo, luzindo

Ou atadura, escondendo

Vindo escura

Ou pegajosa lambendo

Vinda do alto

Ou das ferraduras

Memoriosa se dizendo

Calada ou nova

Vinda da coitadez

Ou régia numas escadas

Subindo

Amada

Torpe

Esquiva

Bem-vinda. ${ }^{3}$ (HILST: IV, 32)

Essa imagem erótica, potencializada pela nasalização dos gerúndios e no interior das palavras, o que dá ao texto um aspecto escorregadio, serpenteia pelos diversos livros da autora, ora associada à morte, ora à própria palavra poética: duas faces do mesmo ser desejoso do Outro. Isso pode ser comprovado no poema III de Da Noite, texto que compõe o volume Do Desejo (2004):

Vem dos vales a voz. Do poço.

Dos penhascos. Vem funda e fria

Amolecida e terna, anêmonas que vi:

Corfu. No mar Egeu. Em Creta.

Vem revestida às vezes de aspereza

Vem com brilhos de dor e madrepérola

Mas ressoa cruel e abjeta

Se me proponho ouvir. Vem do Nada.

Dos vínculos desfeitos. Vem dos ressentimentos.

E sibilante e lisa

Se faz paixão, serpente, e nos habita. (HILST, 2004: 31)

O poema refere-se à voz ou à palavra do poeta e funda a semelhança morte-serpentepensamento, no aspecto escorregadio que se move de dentro do ser-poema. Se a imagem da cobra não aparece mais explicitamente em Da Morte..., o poema Da Noite lançado em 1992, doze anos após aquele, desenha o que em ícone já se reconhecia.

Mas, chegar à morte é ter o conhecimento, ou seja, a via de acesso ao uno. Como que repetindo a função bíblico-inaugural de detentora do conhecimento (sophia), a serpente (ophis) relaciona-se com o proibido e a sua transgressão: a procura pelo conhecimento do sagrado metafísico (e, conseqüentemente, pelo auto-conhecimento ${ }^{4}$ ) nas espirais labirínticas do erótico.

\footnotetext{
${ }^{3}$ Schenberg (2001: 130-1) ressalta a descoberta científica de que o homem possui como que três cérebros: um de réptil, um de mamífero e um mais racional, que é o córtex cerebral, parecido com um computador. É no cérebro mais antigo, de réptil, onde ocorrem mais reações químicas e onde estão as idéias mais profundas, além do fomento para a criação poética e grande parte da matemática.

4 "A serpente come a própria cauda. Mas é só depois de um longo tempo de mastigação que ela reconhece no que ela devora o gosto de serpente. Ela pára, então... Mas ao cabo de um outro tempo, não tendo nada mais para comer, ela volve a si mesma... Chega então a ter a sua cabeça em sua goela. É o que se chama 'uma teoria do conhecimento" (CAMPOS, 1984: 113).
} 
Todavia, mais do que símbolo, a serpente se desenha iconicamente, serpenteando em especulações com suas idas e vindas frenéticas. Inscrita nas curvas dessa serpent-penser, o ser mutante morte é sensualmente corporificado até se dar a fusão dos corpos: "Duas fortes mulheres / Na sua dura hora.” (HILST: II, 30).

Juntas. Tu e eu.

[...]

Dois cortes.

Duas façanhas.

E uma só pessoa (HILST: XXX, 58)

Tal procedimento visa a antecipar-se ao próprio tempo, por meio do espaço físico do poema, numa geometria projetiva que abandona distâncias ou ângulos (SCHENBERG, 2001: 102), no intuito de reconciliar espírito e matéria, razão e sensação: “Como virás, morte minha? [...] Como me tomarás?” (HILST: V, 33); “Quando é que vem?” (HILST: XXIII, 51).

Desvendar-lhe o "como” é encontrar sua essência, todavia, ainda num espaço impreciso do tempo. A perseguição se faz em via dupla: da mesma forma que o eu-poético persegue a morte, a morte o persegue como assinala, em ícone, o verbo no futuro “tomarás”. Mais do que a presença é a onipresença da morte, a despeito do descascamento imagético que ora satura, ora esvazia a imagem à medida que vão se sucedendo os nomes: “Brevíssima contração: / Te reconheço, amada” (HILST: VI, 34).

Por mais que a imagem primeira encapsule outras, ela nunca será “exatamente”. Apenas no breve momento entre os movimentos de contração e expansão, ou seja, no momento da apreensão do texto poético, é que a imagem é (o que faz lembrar o instante-já clariceano). Nesse sentido, pode-se concluir que pensar / reconhecer / amar a própria morte é antecipar-se e morrer quantas vezes a razão permitir. Tal processo, conseqüentemente, leva ao renascimento proporcional às mortes ocorridas, graças ao pensamento que não segue uma direção única, mas repensa-se a si mesmo num fluxo-refluxo, cuja dança o intelecto não pode dar como acabada ou passível de ser concluída:

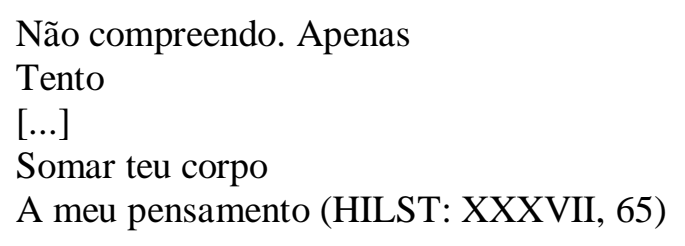

A morte, na sua parcela física relacionada ao corpo-matéria, possui também elementos abstratos relacionados à não-vida e às questões primordiais da metafísica. Daí que, em nome da fusão do abstrato (pensamento) ao concreto (corpo), a poeta constrói incríveis manobras intelectivas na caracterização de uma morte, cujo conceito encontra-se entre ambos, ou na relação entre opostos: 
Teu nome é Nada

Um sonhar do universo

No pensamento do homem:

Diante do eterno, nada" (HILST: XX, 48)

Porque é feita de pergunta

De poeira.

Articulada, coesa

Persigo tua cara e carne

Imatéria. (HILST: XIV, 42)

Se infinita sobre a minha Idéia

Se assemelha à Vida (HILST: XVII, 45)

A morte-vida é incitada a pensar-se também, pois é ela quem ressoa como um eco na imaginação da poeta: “Morte, imagina-te” (HILST: VII, 35). Mas, se a imaginação é da poeta, se o temor é da poeta, a morte é ela mesma espelhada nas imagens que dançam em sua consciência: “Morte, te tomo [...] E intensa me retomo sob o sol” (HILST: XXIV, 52)

Juntas. Tu e eu.

[...]

Dois cortes.

Duas façanhas.

E uma só pessoa (HILST: XXX, 58)

Como se observa no desenrolar da análise, o movimento coreográfico de palavras no interior de outras possibilita os deslocamentos posicionais das imagens suscitadas no poema. Tais imagens reverberam numa espiral labiríntica, que ora se expande, ora se contrai no raciocínio; ora vai, ora volta, serpenteando o pensamento e espelhando a imagem da poeta em sua própria construção ${ }^{5}$ :

Lenho, olaria, constróis

Tua casa no meu quintal.

E desde sempre te espio

[...]

Vezenquando te volteias

Para que eu não me esqueça. (HILST: VIII, 36)

Rasteja, voa, passeia

Com toda lenteza

Sobre a minha Idéia

Em espiral. (HILST: XVII, 45)

Fatalmente, a idéia da morte que volta a si mesma desemboca na reflexão metalingüística. $\mathrm{O}$ percurso labiríntico, não oferecendo saída, promove, por meio do jogo de espelhos, o encontro com a própria poesia. A investigação da morte, pretexto para o auto-reconhecer-se da poeta naquilo que só a ela pertence, torna-se barro edificado no papel:

\footnotetext{
5 “Como! Isto também sou eu - disse a serpente retorcendo-se para a ponta longínqua de sua cauda, e ela se espantava de fazê-la remexer-se de tão longe, sua e não sua!” (CAMPOS, 1984: 113).
} 
Ao invés de Morte

Te chamo Poesia

Fogo, Fonte, Palavra viva.

Sorte. (HILST: XIX, 47)

A Morte, na verdade, figura como o fio condutor do seu ser-pensar e material poetizante intuitivo submetido ao rigor plástico do raciocínio intelectivo-poético. Portanto, sabendo-se perfil de um mesmo dracma, a poeta manipula a morte-consciência-poesia, através dos instrumentos da própria poética:
E minha voz e cantiga?
Meu verso, meu dom
De poesia, sortilégio, vida?
Ah, leva-os contigo.
Por mim. (HILST: XI, 39)

Se a vida e a morte são condições imanentes à própria poesia, ao poeta cabe a utilização instrumental, o versejar forte, devorador de si mesmo, e, parafraseando Valéry, o pensar levado às últimas conseqüências:

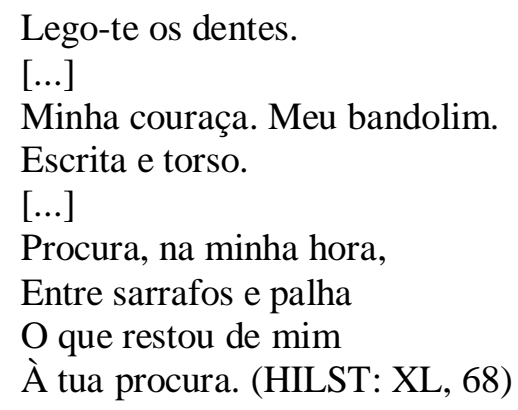

A partir de dois processos imaginativos diferentes - no qual um vai da palavra à imagem e, outro, da imagem à expressão verbal - a poeta cria um conceito sensível-inteligível da morte. A sucessão de nomes/imagens, cada uma englobando e ampliando a anterior, aponta para uma visão plural e multifacetada do ser num conceito sensível-inteligível que, paradoxalmente, firma sua precisão nesse ambiente impreciso da poesia.

A paixão especulativa, portanto, conduz o eu-lírico do abstrato (tema) para o concreto (imagens) e deste para uma subjetividade exasperada, pois que, na tentativa de limitar seu objeto, amplia-o em demasia desfocando sua forma e visibilidade/dizibilidade. Dessa forma, sob o invólucro da imaginação, a metafísica se inscreve enquanto morte da própria palavra e contínuo renascimento vindo de seu infinito possível e de seu inominável imanente e permanente: é a poesia metafísica de Hilda Hilst tentando traduzir uma totalidade que escapa ao homem e ao poeta.

Conclui-se, então, que o fracasso na presentificação do ser é o sucesso da representação poética, que se alimenta desse indizível essencial ao ser humano. Mas, essa indizibilidade faz com 
que o inominável continuamente escape-lhe pelos vãos dos dedos. Por isso, a poeta ousa, ainda, atravessar os limites da idéia em favor das exigências sensórias.

\section{Do erotismo da forma à pornografia vernacular}

A busca dos aspectos sensíveis para tornar visível o invisível intensifica-se no volume Poemas malditos, gozosos e devotos (2005):

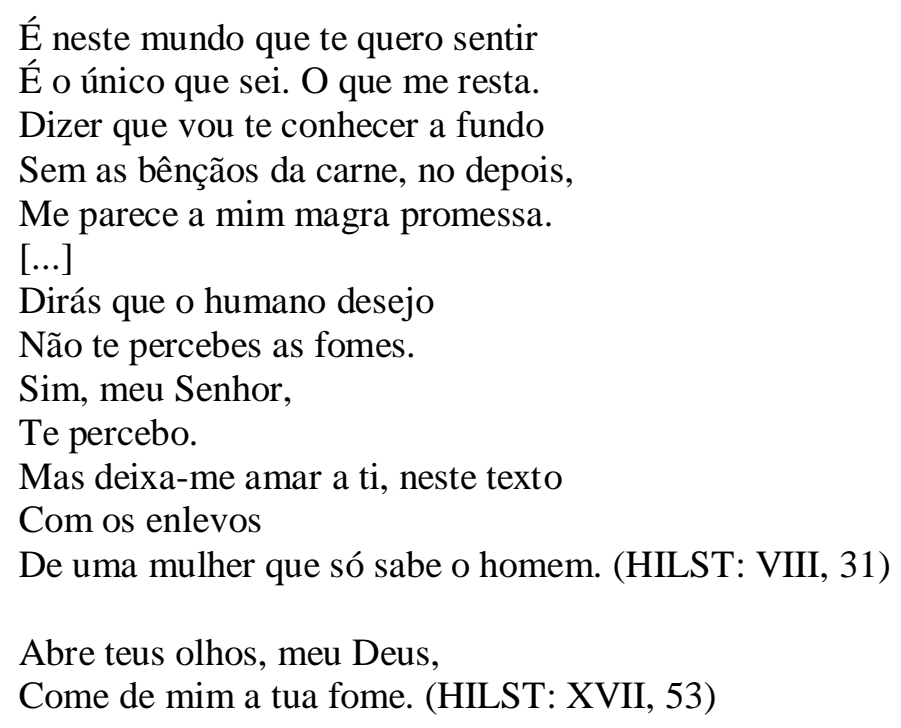

Observa-se, no desenrolar dessa composição, a construção do próprio espaço como imagem da idéia de Deus. Em Newton a concepção de espaço concordava com sua idéia a respeito de figura divina: para ele, “é como se Deus tivesse órgãos sensoriais, e o espaço fosse exatamente o sensório de Deus” (SCHENBERG, 2001: 39). No espaço, tanto físico quanto poético, embora haja um principio causal, é a simultaneidade que prevalece.

Essa postura agressiva da poeta intensifica-se ainda mais no volume Do desejo (2004): o sexo será continuamente reclamado por se tratar do mais primitivo contato do homem com o outro e, por isso, essencial para tocar o sensível, o inefável: "Para pensar o Outro, eu deliro ou versejo. / Pensá-LO é gozo. Então não sabes? / INCORPÓREO É O DESEJO” (HILST: X, 26); “Extasiada, fodo contigo / Ao invés de ganir diante do Nada” (HILST: I, 17)

O corpo físico vai se tornando o único lugar possível ao encontro com Deus:

Olhando o meu passeio

Há um louco sobre o muro

Balançando os pés.

Mostra-me o peito estufado de pêlos

E tem entre as coxas um lixo de papéis:

- Procura Deus, senhora? Procura Deus?

E simétrico de zelos, balouçante

Dobra-se num salto e desnuda o traseiro. (HILST: III, Via Espessa, 67) 
A imagem do ânus como o "lugar” físico possível para se construir a idéia do sagrado é uma constante que reaparece por toda a obra hilstiana e possui grande carga de significação, pois se trata de um corpo "estranho" nas artes poéticas que abala o espaço impreciso do poema. Entretanto, o retorno ao corpo físico desnuda um processo metafísico que não busca extrapolar o corpóreo, mas inscrever-se nele mesmo, reforçando-o através de signos “proibidos”.

A parcela de poemas pornográficos hilstianos é carregada por nomes que, freqüentemente, não habitam o solo sagrado da "grande poesia" e que, no entanto, ao modo do conceito recriado da Morte, por meio do movimento que impossibilita a nomeação final do objeto, atingem status poético. Ou seja, trata-se de uma variante da mesma técnica de enumeração nomeadora, observada pela perspectiva geometrizante do pensamento que compõe uma linha, ora mirando o sublime, ora o grotesco.

Todavia, aqui, não se parte de um conceito informe, mas de uma imagem que possui uma forma físico-concreta. Os lugares mais recônditos do corpo, orifícios ou protuberâncias, desde sempre escondidos para não se mostrar/revelar, são os espaços mais promissores para a construção do conhecimento. Isso porque o corpo é o que há de material mais imediato ao homem, é através dele que o homem se reconhece como indivíduo (MORAES, 2002: 60). Portanto, física e textualmente, a poeta foca os genitais masculinos e femininos, expondo seus contornos e anomalias, mais uma vez, na tentativa de delimitar uma forma no espaço.

A metafísica dessa “antipoesia” consiste em virar a poesia ao avesso metafórico, isto é, ao invés de partir de uma metáfora poética para a coisa em si, usa-se seu nome-mesmo. Evidentemente, o princípio metafórico encontra-se no interior de todo processo de simbolização (PAZ, 1982: 41), entretanto, nestes textos, o que se chama não-metáfora ou nome-mesmo é uma imagem que se pretende estática.

Paul Ricoeur (2000) denomina "metáfora morta” aquela que não se expande em significação. Ele observa ainda que a usura da metáfora faz com que ela se pareça com o próprio conceito. Assim, se a metáfora poética causa estranhamento, pois funciona como um véu que encobre uma imagem primeira (a qual cabe ao leitor des-velar e estabelecer a relação entre ambas), na pornografia hilstiana ocorre um processo inverso: a poeta dá, de chofre, sem véu, a imagem primeira em zoom, impossibilitando o des-velamento.

Entretanto, por se tratar do espaço da poesia, o estranhamento persiste, pois a relação insiste em se materializar a despeito da artimanha poética que entregou o processo concluído. Diz-se artimanha, porque a poeta quebra com o princípio erótico da poesia, o de não revelar, mas ocultar, instituindo assim a pornografia da palavra (BARTHES, 1999: 16). A pornografia lingüística, por sua vez, leva à perda da aura de mistério, a qual coincide com a implosão significativa. Nesse 
contexto, o leitor sente-se privado de "lucidez poética", ou seja, de dispor, analisar, imaginar, abstrair, dar forma ao pensamento.

Resta-lhe, portanto, persistir na elaboração de um diagrama relacional, pois, mesmo abalado o processo de investigação metafórica, cumpre-lhe elaborar, a partir dessa imagem primeira, um véu que a encubra, já que “o objeto idêntico a si mesmo perde a sua realidade” (MORAES, 2002: 69).

O exposto pode ser exemplificado com o poema O reizinho gay de Bufólicas (2002), livro que complementa a trilogia narrativa pornográfica:

Mudo, pintudão

O reizinho gay

Reinava soberano

Sobre toda a nação.

Mas reinava...

APENAS...

Pela linda peroba

Que se lhe adivinhava

Entre as coxas grossas

Quando os doutos do reino

Fizeram-lhe perguntas

Como por exemplo

Se um rei pintudo

Teria o direito

De somente por isso

Ficar sempre mudo

[...]

E daí em diante

Sempre que a multidão

Se mostrava odiosa

Com a falta de palavras

Do chefe da Nação

O reizinho gay

Aparecia indômito

Na rampa ou na sacada

Com a bronha na mão.

E eram ós agudos

Dissidentes mudos

Que se ajoelhavam

Diante do mistério

Desse régio falo

Que de tão gigante

Parecia etéreo

E foi assim que o reino

Embasbacado, mudo

Aquietou-se sonhando

Com seu rei pintudo.

Mas um dia...

Acabou-se da turba a fantasia

$\mathrm{O}$ reizinho gritou

Na rampa e na sacada

Ao meio-dia:

[...] 


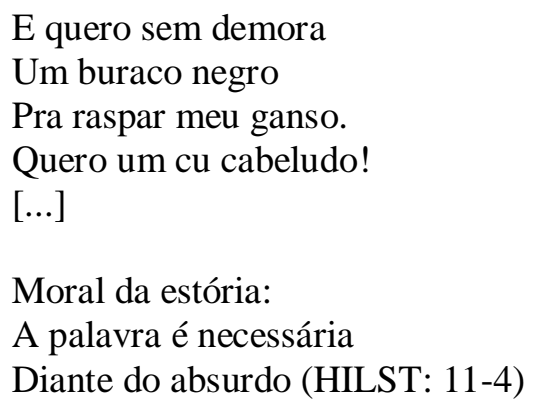

Observa-se que pintudão, peroba, pintudo, bronha são termos não usuais poeticamente e remetem, apenas, à forma física, ou seja, não se expandem ou encapsulam outros significados. Nesse sentido, tais termos, se não literais, podem ser considerados primitivos, pois não se bifurcam para outros campos semânticos, carregando sempre a mesma imagem (pênis). Por isso, esses significantes sobressaem na leitura e desorientam a apreensão metafórica, pois se "o não-dito da metáfora é a metáfora usada” (RICOEUR, 2000: 439), eles perderam seu grau de metaforicidade ao dizer o todo do que representam.

A auto-revelação do poema, ou o pornográfico, ao expor o que deve estar oculto, leva à mudez da palavra. A metáfora morta, estancada nela mesma, acaba não dizendo nada e instaurando o vazio de significado. Entretanto, conforme Schenberg, o vazio é o estado fundamental do campo, pois aponta, tanto para a falibilidade sígnica, quanto para a potência da palavra que não se rende ante ao continuum do pensamento.

Portanto, reviver a metáfora morta, ou descascá-la em busca de uma imagem outra, é desmascarar o falso conceito. Cabe ao leitor reavivar o símbolo, num movimento especulativo, acionando as oposições características da metafísica: sensível/espiritual, sensível/inteligível, sensível/sentido.

O espaço dessas relações vacila entre a harmonia-desarmonia, porém, é na desarmonia, ou no caos criador, que a metáfora morta pode ser reavivada. A desarmonia, provocada pela colisão de opostos lingüísticos - termos no aumentativo e diminutivo (pintudão/reizinho), termos cultos e chulos (indômito/pintudo) - revelam, através de elementos díspares, um conflito: rei condensa a semântica da desigualdade, gay condensa a semântica da igualdade. Diante dessa situação, o reinado dá-se “apenas” e “a(s) penas”, conforme a ênfase adverbial.

Ademais, ao ser surpreendido no final com uma "moral da estória”, o leitor é incitado ainda mais a "velar para desvelar” e, assim, chegar a um conceito. O “absurdo” é justamente aquilo que escapa à palavra, o indizível/inominável que não se submete ao dizer/nomear. Portanto, é a metafísica descendo aos lugares mais baixos para pensar a relação entre a palavra poética e o objeto de representação. 
Na expectativa de desvendar o enigma poético e se a palavra é "necessária diante do absurdo”, é preciso se agarrar a uma palavra para organizar o espaço caótico do texto. O versoadvérbio “APENAS...”, grafado em enfáticas letras maiúsculas e, à primeira vista, desnecessário à compreensão, sozinho não remete à imagem alguma, mas transforma-se em imagem atrativa, ou seja, estabelece novas associações significativas: (A)PENAS > penas > pena > pintudão > pinto > Reizinho > pintudo > ganso. A seqüência garante ao leitor um véu e a possibilidade de retirá-lo. Todavia, ao esbarrar, novamente, na moral da estória, ele se surpreende com uma ironia sagaz: o texto é absurdo pelo seu alto grau de evidência.

O leitor, não estando preparado para o óbvio, insiste em atribuir-lhe roupagens desnecessárias, pois o que depreende da poesia não é um conhecimento extrapoético, mas intrapoético. É poesia que fala dela mesma e da imanência metafísica na impossibilidade de nomeação/conhecimento integral, tanto do abstrato quanto do concreto. Talvez por isso, a parcela pornográfica de Hilda Hilst tenha sido tão pouco entendida: justamente por não ser.

Observa-se, assim, que o espaço do poema configura-se como um campo de batalha para a linguagem resolver seus conflitos lingüísticos e semânticos. No interior destas “metáforas-mortas”, é possível observar uma situação poético-físico-textual que rompe com a hierarquia vernacular, em favor da capacidade lingüística de presentação do mundo. Somada a esta, uma situação de busca metafísica pelo conhecimento, que não se rende à extrapolação do corpóreo, mas investe no retorno ao corpo físico, desnudando signos proibidos. Linhas que se cruzam em significação, mas não se fecham em nenhum significado.

Na arena poética hilstiana, expõe-se o conflito mudez x falo (o pênis desdobrado em língua fálica, instrumento para a celebração da fecundidade da palavra). Todavia, materializa-se na anomalia fálica, exposta no poema pelo seu tamanho desproporcional, a impotência da palavra em dizer o todo. A verdade poética não está no que se fala, mas no que se cala no poema e que traduz a dialética do procedimento metafísico que é a "ânsia de perseguir a emoção abstrata em termos de coisas, essa coisificação dos conceitos através dos sentidos” (CAMPOS, 1998: 128. Grifos do autor).

A metáfora morta esconde ao ser exposta: há sempre um buraco, um vazio, uma ausência que constituem o empreendimento poético, conforme se verifica no fragmento abaixo:

Dissidentes mudos
Que se ajoelhavam
Diante do mistério
Desse régio falo
Que de tão gigante
Parecia etéreo
E foi assim que o reino 
Embasbacado, mudo

Aquietou-se sonhando

Com seu rei pintudo (HILST: 12)

Embora possam parecer versinhos tolos, o contato primitivo e carnal com o corpo físicotextual, escancarado em termos considerados marginais na poesia, tem intenção fundadora de linguagem. Linguagem inaugural fundada/fundida ao corpo como via de acesso ao conhecimento do mundo. Recriar o sensível carnal destituído do elemento poético, e, a partir daí, provocar a sua percepção por meio da exploração e investigação do mundo simbólico:

E quero sem demora

Um buraco negro

Pra raspar meu ganso.

Quero um cu cabeludo! (HILST: 14)

Mais uma vez, o cu como o buraco negro cósmico engole tudo que está ao seu redor. O pornográfico nivela a linguagem, possibilitando o embate entre as palavras e mostrando que, uma vez no poema, a palavra pornográfica - ou “antipoética” - é parte integrante, regra e não exceção: “Moral da estória: / A palavra é necessária / Diante do absurdo” (HILST: 14).

Sem a palavra antipoética o poema torna-se mudo, tanto no sentido de inexpressivo, como no de mudança; seria outro que não ele mesmo. Nesse sentido, se necessária à materialização do poema, a palavra antipoética já se tornou poética. Assim, partindo do grotesco, visto como elemento exterior, Hilda Hilst elabora uma revisão conceitual dos “nomes feios” tornando-os nomes poéticos, ou atribuindo-lhes poeticidade.

A paixão especulativa, na vertente pornográfica, conduz o eu-lírico do concreto (imagens) ao abstrato (inominável) já que, na tentativa de reduzi-lo a si próprio, aproxima-se em demasiado desfocando, também, sua visibilidade e dizibilidade. Elabora-se, portanto, um processo análogo ao processo seguido em Da morte..., porém em direção oposta. Se no primeiro a poeta, a partir de infinitas imagens, desenha uma linha ascendente em expansão para construir um conceito abstratoconcreto, aqui, a poeta busca fixar na (pretensa) imobilidade da mesma imagem, um ponto para o qual tudo converge, construindo um conceito concreto-abstrato que mesmo parecendo dizer, ainda assim, não diz.

\section{Referências}

BADIOU, Alain. Pequeno Manual de Inestética. São Paulo: Estação Liberdade, 2002.

BARTHES, Roland. O prazer do texto. 5ed. São Paulo: Perspectiva, 1999.

CAMPOS, Augusto de. Verso, Reverso, Controverso. São Paulo: Perspectiva, 1988.

. Paul Valery: a serpente e o pensar. São Paulo: Brasiliense, 1984.

CAMPOS, Haroldo de (org.). Ideograma: lógica, poesia, linguagem. São Paulo: EdUSP, 2000. 
HILST, Hilda. Bufólicas. São Paulo: Globo, 2002.

. Da Morte. Odes Mínimas. São Paulo: Globo, 2002. . Do Desejo. São Paulo: Globo, 2004. . Poemas malditos, gozosos e devotos. São Paulo: Globo, 2005.

MORAES, Eliane Robert. O corpo impossível. São Paulo: Iluminuras, 2002.

PAZ. Octavio. O arco e a lira. Rio de Janeiro: Nova Fronteira, 1982.

POUND, Ezra. A arte da Poesia. São Paulo: Cultrix, 1991.

RICOEUR, Paul. A Metáfora Viva. São Paulo: Edições Loyola, 2000.

SCHENBERG, Mário. Pensando a Física. São Paulo: Landy, 2001. 